\title{
Morphological Characterization of Gallstones in Cholecystectomy Specimens: A Four Years Study
}

\author{
Dr. Navyashree $\mathrm{N}^{1^{*}}$, Dr. Sujata S Giriyan ${ }^{2}$ \\ ${ }^{1}$ Resident Doctor, Department of Pathology, Karnataka Institute of Medical Sciences, Hubballi, Karnataka, India \\ ${ }^{2}$ Professor and Head, Department of Pathology, Karnataka Institute of Medical Sciences, Hubballi, Karnataka, India
}

\begin{abstract}
DOI: $10.36348 /$ sjpm.2020.v05i02.001 $\quad$ | Received: 13.01.2020 | Accepted: 02.02.2020 | Published: 09.02 .2020
*Corresponding author: Dr. Navyashree N
\end{abstract}

\section{Abstract}

Background: Gallstones are the major culprits for gallbladder pathologies. More than 95\% of biliary tract disease is attributable to cholelithiasis (gallstones). Most patients are unaware of the disease and remain asymptomatic for life. Aim: To determine morphological characterization of gallstones in cholecystectomy specimens to understand its association with etiology. Material and Methods: All cholecystectomy specimens having gallstones received at the Department of Pathology over a period of four years were studied for morphological characterization. Results: Out of 178 gallbladders showing calculi, patients of $5^{\text {th }}$ and $7^{\text {th }}$ decade $(24.15 \%$ and $21.92 \%)$ were commonly affected and majority were females (69\%) when compared to males $(31 \%)$. Most common calculi were mixed type of stones $(64.04 \%)$. $48.88 \%$ gallbladders were having round to oval shaped calculi, $24.15 \%$ were polyhedral, multifaceted and $26.97 \%$ were irregular in shape. Conclusion: The population of the present study showed mixed type of calculi as common observation which depicts its etiology of change in lifestyle with following western diets and concurrent infectious cause.

Keywords: Cholelithiasis, gallstones, multifaceted.

Copyright @ 2020: This is an open-access article distributed under the terms of the Creative Commons Attribution license which permits unrestricted use, distribution, and reproduction in any medium for non-commercial use (NonCommercial, or CC-BY-NC) provided the original author and sources are credited.

\section{INTRODUCTION}

Gallstones are the major culprits for gallbladder pathologies. More than $95 \%$ of biliary tract disease is attributable to cholelithiasis. Gallstones afflict $10 \%$ to $20 \%$ of adult populations in developed countries [1]. The prevalence varies with age, sex and ethnic group. It occurs predominantly in females [2]. Most patients are unaware of the disease and remain asymptomatic for life. The current changes in lifestyles of individuals pertaining to indulgence in unhealthy fatrich food, lack of exercise, obesity, sedentary lifestyles and various other factors have once again focused our attention to gall stones and diseases of the gall bladder [3].

CHOLELITHIASIS is a common disorder, afflicting $10 \%$ to $20 \%$ of adult population in developed countries [1]. It has been called as costly digestive disease in developed countries [4]. Its incidence has markedly increased in Asian countries owing to adoption of western type of dietary habits [5].

The estimated prevalence of Gall stone disease in India has been reported as $2 \%$ to $29 \%$. In India, this disease is ten times more common in the North India than in South India. Hormones, repeated pregnancies, obesity have been implicated as the major factors in females, who are more prone for gall bladder disease $[6,7]$. Oestrogen exposure, including oral contraceptive use and during pregnancy increases the expression of hepatic lipoprotein receptors and stimulates hepatic HMG-CoA reductase activity, enhancing both cholesterol uptake and biosynthesis respectively. The net result is excess biliary secretion of cholesterol. Common variant of sterol transporter encoded by ABCG8 gene is associated with increased risk [1].

Gallstones predominantly composed of cholesterol, bilirubin and calcium salts with lesser amounts of other constituents. These are classified into cholesterol and non-cholesterol gallstones based on the relative amount of cholesterol in the stones. Cholesterol stones are common in Western countries whereas pigment stones are common in other parts of the world including Asia [8]. Cholesterol gallstones are composed of cholesterol crystals agglomerated by a mucin glycoprotein matrix. Non-cholesterol gallstones include black or brown pigment stones. Black pigment stones are formed from calcium salts of unconjugated bilirubin 
in a polymerized matrix and brown pigment stones are formed within bile ducts and contain bacterial degradation products of biliary lipids, calcium salts of fatty acids, unconjugated bilirubin and precipitated cholesterol [8].

\section{Pathogenesis of Stone Formation}

Cholesterol stones: When cholesterol-tophospholipid ratio exceeds 1, that is exceeding solubilizing capacity of bile (supersaturation), cholesterol can no longer remain dispersed and nucleates into solid cholesterol monohydrate crystals [1]. An increase in biliary cholesterol output- either due to increased synthesis or increased uptake by hepatocytes is the most common cause of supersaturation and subsequent stone formation [9]. Cholesterol supersaturation can also arise as a consequence of bile acid hyposecretion $[10,11]$.

Pigment stones: As aetiology, associated clinical conditions, morphology and chemical composition are different and hence it is necessary to distinguish between black and brown pigment stones [12]. Unconjugated bilirubin being precursor for calcium bilirubinate plays a central role in the formation of both brown and black pigment stones.

Brown stones: Any condition resulting in elevated levels of unconjugated bilirubin can predispose to stone formation. Biliary infection contributing to bile stasis is a common cause of brown stones, as bacterial overgrowth generates hydrolases that can form free bile acids from conjugated bile salts. Hence the bacteria are present within the matrix of most brown stones [13].

Black stones: are not associated with bacterial infection. It originates from an increment in the secretion of bilirubin conjugates as occurs in haemolysis [14] and chronic alcoholism, followed by non-bacterial enzymatic or non-enzymatic hydrolysis. (Other conditions associated with black gallstones include malaria, pancreatitis, total parenteral nutrition and advanced age) Calcium bilirubinate sludge containing an increased amount of phospholipid forms the core of pigment gallstones. Carbohydrate rich diets stimulate enzymes which are important in the synthesis of phospholipidsm [15].

Gallstone formation is also favoured by bile stasis due to gallbladder dyskinesia resulting from gallbladder wall pathology and also due to exposure of gallbladder mucosa to high concentrations of mucus, calcium and lipids [16].
Cholelithiasis produces diverse histopathological changes in gallbladder mucosa namely acute and chronic cholecystitis, granulomatous inflammation, cholesterolosis, glandular hyperplasia, metaplasia, dysplasia, and carcinoma [17].

\section{MATERIAL AND METHODS Source of Data}

The present study was done on all the cholecystectomy specimens showing calculi received at the Department of Pathology of a tertiary care hospital over a period of four years June 2014 to May 2018.

\section{Sample Size}

All the cholecystectomy specimens showing calculi (178) received at the Department of Pathology, over a period of four years which satisfied inclusion and exclusion criteria were considered in the present study.

Inclusion criteria: All cholecystectomy specimens showing calculi were included in the study.

Exclusion criteria: Autolysed, gangrenous specimens and also specimens without calculi were excluded from this study.

\section{METHOD OF COLLECTION OF DATA}

The gall bladder specimens were collected in $10 \%$ formalin following scrutinizing the patient details and identity. The gallbladder specimens were cut and allowed to fix in fresh formalin for 24 hours. Detailed gross examinations were carried out and descriptions of the specimens were noted. Tissue bits were taken from representative areas of the fundus, body and neck of the gall bladder for histopathological examination. Additional tissue bits were taken from abnormal appearing areas.

This was followed by processing with routine histological techniques for paraffin embedding and sectioning at 3-5micron thickness. The tissue sections were placed on a slide warmer for deparaffinisation and further deparaffinisation using xylene, followed by Haematoxylin and Eosin stain. Special stains were used wherever required. Microscopical examination was done under different objective powers of light microscope and changes in all cases were noted.

Statistical Analysis: Statistical analysis was done using SPSS software.

\section{RESULTS}

Out of 178 gallbladders showing calculi, majority $123(69 \%)$ were from females when compared to males $(55,31 \%)$ (Table-1). 
Table-1: Sex distribution of gallbladders with calculi

\begin{tabular}{|l|l|l|l|}
\hline Gross examination & $\begin{array}{l}\text { Number of males } \\
\text { (Percentage \%) }\end{array}$ & $\begin{array}{l}\text { Number of Females } \\
\text { (Percentage \%) }\end{array}$ & Total \\
\hline Gallbladders with calculi & $55(31 \%)$ & $123(69 \%)$ & $178(100 \%)$ \\
\hline
\end{tabular}

Age distribution based on calculi in the present study

Among them, $5^{\text {th }}$ decade was most commonly affected with 43 cases $(24.15 \%)$, followed by $7^{\text {th }}$ decade 39 $(21.92 \%)$ (Figure-1).

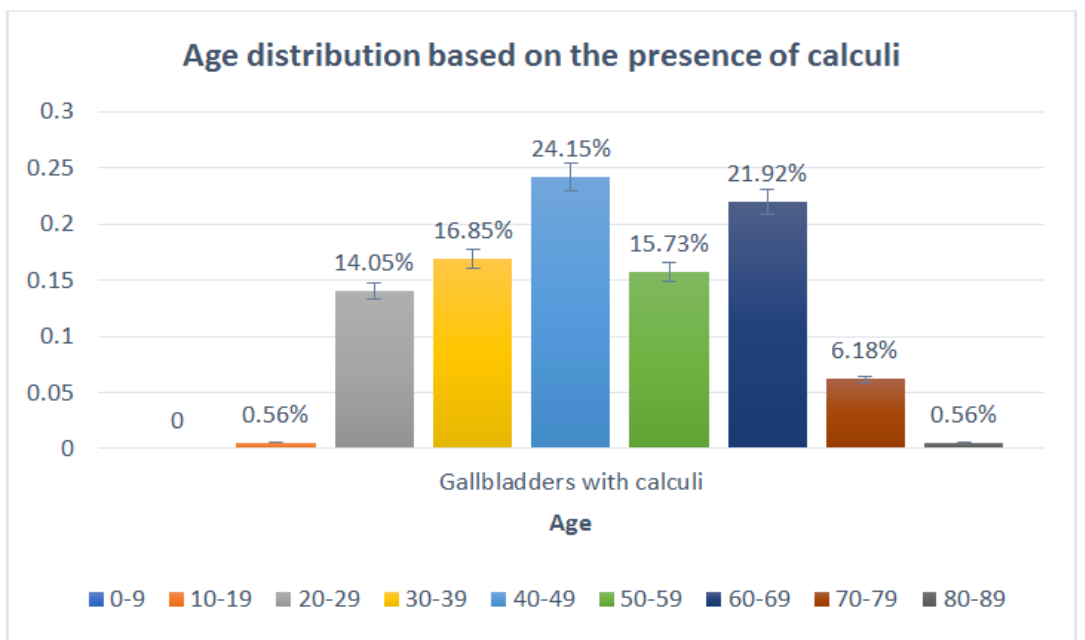

Fig-1: Age distribution based on calculi in the present study

Distribution based on type of calculi in the present study

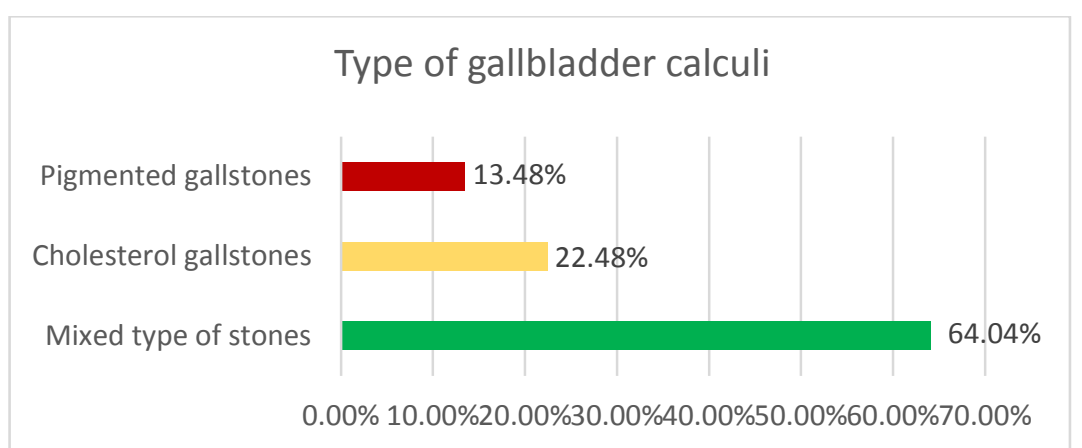

Fig-2: Distribution based on type of calculi in the present study

Most common calculi were mixed type of stones (114 gallbladders, 64.04\%), followed by cholesterol gallstones (40 gallbladders, 22.48\%) and least was pigmented gallstones (24 gallbladders, $13.48 \%$ ) (Figure-2).

Table-2: Distribution based on number of calculi in the present study

\begin{tabular}{|c|c|c|c|}
\hline Type of gallbladder calculi & $\begin{array}{c}\text { Single } \\
\text { calculus }\end{array}$ & $\begin{array}{c}\text { Multiple } \\
\text { calculi }\end{array}$ & Total \\
\hline Mixed type of stones & 25 & 89 & $\mathbf{1 1 4}$ \\
\hline Cholesterol gallstones & 4 & 36 & $\mathbf{4 0}$ \\
\hline Pigmented gallstones & 7 & 17 & $\mathbf{2 4}$ \\
\hline Total & $\begin{array}{c}\mathbf{3 6} \\
\mathbf{( 2 0 . 2 2 \% )}\end{array}$ & $\begin{array}{c}\mathbf{1 4 2} \\
\mathbf{( 7 9 . 7 8 \% )}\end{array}$ & $\begin{array}{c}\mathbf{1 7 8} \\
(\mathbf{1 0 0 \%})\end{array}$ \\
\hline
\end{tabular}

Out of 178 gallbladders showing calculi, $142(79.77 \%)$ were having multiple calculi and remaining 36 $(20.22 \%)$ gallbladders had single calculus. Among the gallbladders with multiple calculi, $89(62.7 \%)$ were mixed stones, $17(12 \%)$ were pigmented stones and 36 $(25.3 \%)$ were cholesterol stones. (Table 2, Figure 4,6,7) 


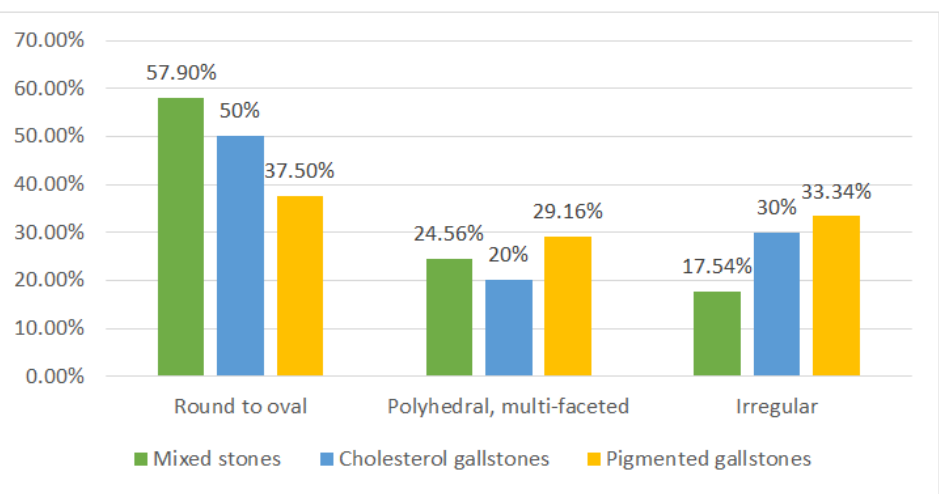

Fig-3: Distribution based on morphology of calculi in the present study

Out of 178 gallbladders with calculi, 87 (48.88\%) gallbladders were having round to oval shaped calculi, 43 (24.15) were having polyhedral, multifaceted calculi and $48(26.97 \%)$ were having calculi irregular in shape (Figure 3, 4 \& 5).

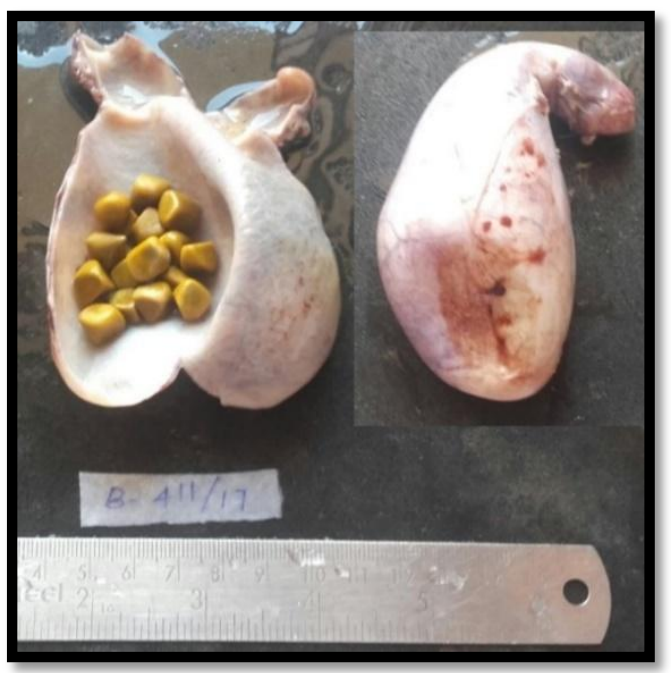

Fig-4: Gross photograph of chronic cholecystitis with calculi, cut section showing multiple, smooth, yellow coloured polyhedral multi-faceted gallstones (Inset showing congested external surface of the gallbladder)

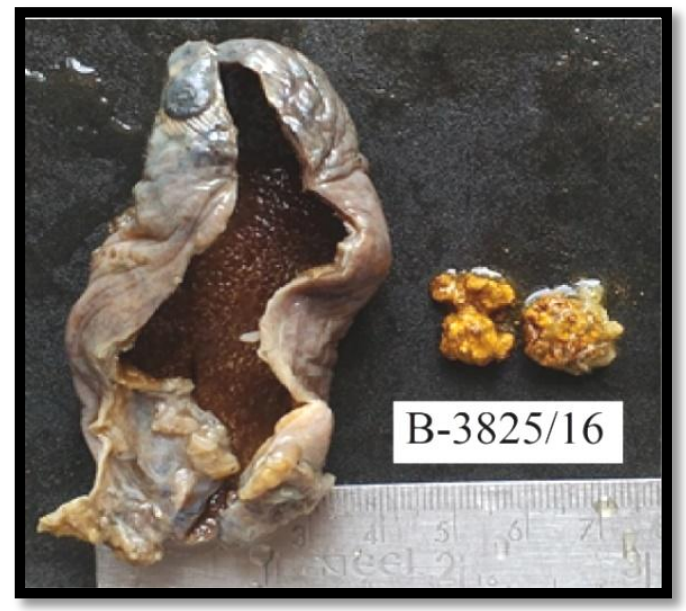

Fig-5: Gross photograph of xanthogranulomatous cholecystitis with calculi showing cut surface of the gallbladder having yellowish brown mucosa. Gallstones were irregular and yellow coloured

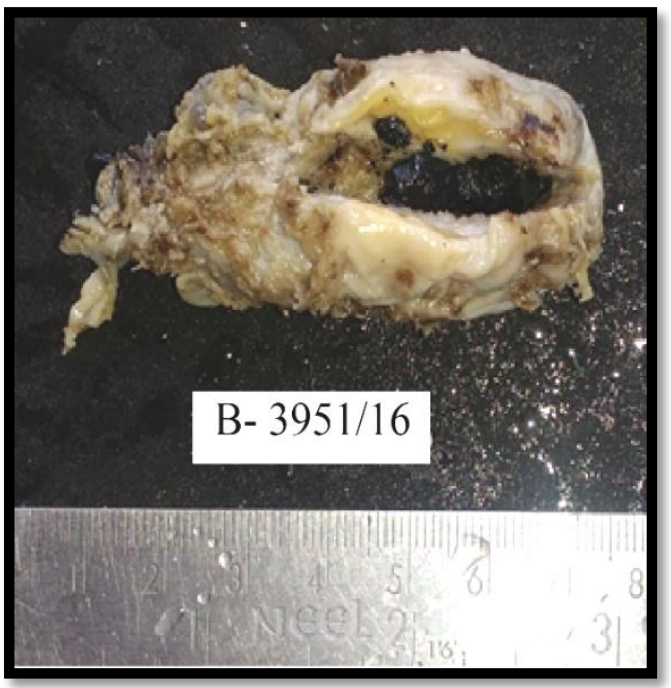

Fig-6: Gross photograph of chronic cholecystitis with calculi showing cut surface of the gallbladder with thickened wall and having irregular black pigmented gallstones

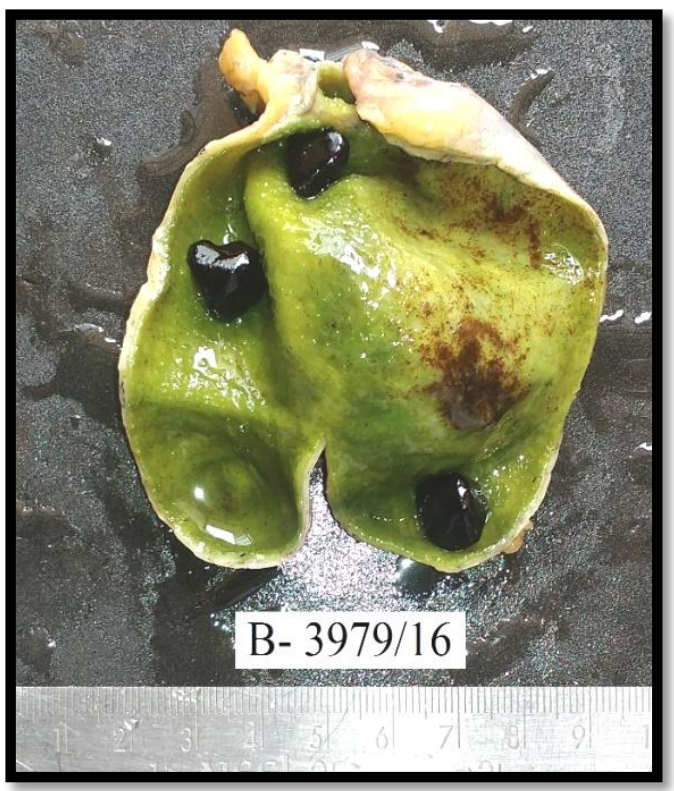

Fig-7: Gross photograph of chronic cholecystitis with calculi showing cut surface of the gallbladder having irregular, smooth and black pigmented gallstones 


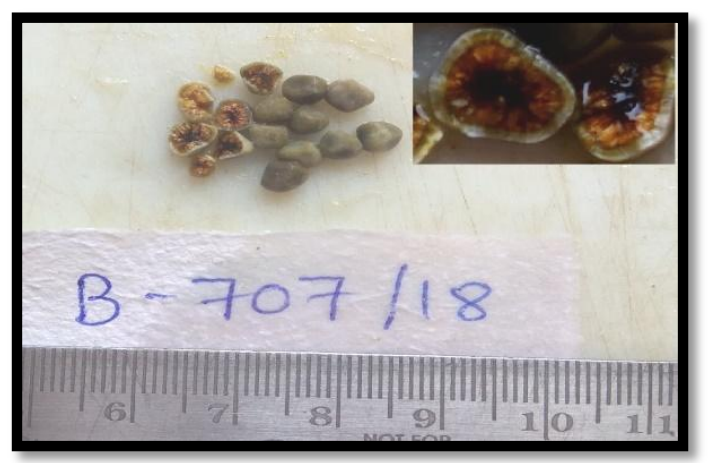

Fig-8: Gross photograph of mixed type of gallstones showing multiple, polyhedral, multi-faceted and brown in colour. Cut section of the stones showing central greyish black core surrounded by radial arrangement of grey brown to grey yellow area (Inset)

\section{DISCUSSION}

In the present study though 316 gallbladder specimens were received only $56.33 \%$ of the cases were associated with gallstones. Whereas studies conducted by Beena D et al., [18], Karlatti SS et al., [19], Awasthi N [20], H Mohan et al., [21] and Goyal S et al., [22] showed higher percentage of gallbladder with calculi $65 \%, 72.73 \%, 95.2 \%, 95.45 \%$ and $90 \%$ respectively. As we received sectioned gallbladders most of the time, surgeons sending the gallbladder specimens without including gallstones may be the cause for the lower values.

Table 3: Comparison of presence of calculi in the present study with other studies

\begin{tabular}{|l|l|l|l|}
\hline Study by & Total number of gallbladders studied & $\begin{array}{l}\text { Total number of gallbladders } \\
\text { with calculi }\end{array}$ & Percentage \\
\hline Awasthi N [20] & 732 & 697 & $95.2 \%$ \\
\hline Beena D et al., [18] & 200 & 130 & $65 \%$ \\
\hline Sharma I et al., [23] & 348 & 305 & $87.64 \%$ \\
\hline H Mohan et al., [21] & 1100 & 1050 & $95.45 \%$ \\
\hline Kumari G et al., [24] & 550 & 437 & $79.45 \%$ \\
\hline Goyal S et al., $[22]$ & 346 & 313 & $90 \%$ \\
\hline Karlatti SS et al., [19] & 143 & 104 & $72.73 \%$ \\
\hline Present study & $\mathbf{3 1 6}$ & $\mathbf{1 7 8}$ & $\mathbf{5 6 . 3 3 \%}$ \\
\hline
\end{tabular}

According to the present study, majority were females $(69 \%)$, which is similar to the studies conducted by Murmu S et al., [25], Awasthi N [20], Mondal B et al., [26] and Kumar H et al., [27].

Comparison of most common type of calculi in the present study with other studies
Mixed type of gallstones was the most common type of gallstones found in the present study $(64.04 \%)$. This was in concordance with the studies conducted by H Mohan et al., [21] (62.3\%), Goyal S et al., [22] (68\%), Nayak G [28] (71.4\%) and Karlatti et al., [19] (81.12\%) suggesting multifactorial involvement of change in dietary habits along with infectious origin.

\begin{tabular}{|c|c|c|c|c|}
\hline Study by & $\begin{array}{l}\text { Total number of } \\
\text { gallbladders with calculi } \\
\text { studied }\end{array}$ & $\begin{array}{l}\text { Most common type of } \\
\text { gallstone present }\end{array}$ & $\begin{array}{l}\text { Total number of } \\
\text { gallbladders showing } \\
\text { most common type } \\
\end{array}$ & Percentage \\
\hline Beena D et al., [18] & 130 & Pigment stones & 117 & $58.5 \%$ \\
\hline H Mohan et al., [21] & 1050 & Mixed type of stones & 686 & $62.3 \%$ \\
\hline Kumari G et al., [24] & 437 & Pigment stones & 540 & $51.03 \%$ \\
\hline Goyal S et al., [22] & 313 & Mixed type of stones & 213 & $68 \%$ \\
\hline Nayak G [28] & 70 & Mixed type of stones & 50 & $71.4 \%$ \\
\hline Karlatti SS et al., [19] & 104 & Mixed type of stones & 84 & $81.12 \%$ \\
\hline Present study & 178 & Mixed type of stones & 114 & $64.04 \%$ \\
\hline
\end{tabular}

Comparison of number of calculi in the present study with other different studies

In the present study, majority $(79.78 \%)$ of the gallbladders with calculi were having multiple gallstones which was comparable to studies done by Nayak G et al., [28] (84.3\%) and Goyal S et al., [22] (69.65\%). 


\begin{tabular}{|l|l|l|l|}
\hline Study by & Total number of gallbladders & \multicolumn{2}{|l|}{ Calculi } \\
\cline { 3 - 4 } & with calculi & Single & Multiple \\
\hline Nayak G [28] & 70 & $11(15.7 \%)$ & $59(84.3 \%)$ \\
\hline Goyal S et al., [22] & 313 & $95(30.35 \%)$ & $218(69.65 \%)$ \\
\hline Present study & 178 & $36(20.22 \%)$ & $142(79.78 \%)$ \\
\hline
\end{tabular}

\section{CONCLUSION}

Out of gallbladders associated with calculi, majority (69\%) were from female patients. Most common age group having gallbladder lesions with calculi was $5^{\text {th }}$ decade $(24.15 \%)$ and majority of the gallstones were found to be mixed type of stones $(64.04 \%)$

These results suggest factors like female gender, lifestyle and dietary habits play a major role in the formation of different types of gallstones. And changing the habits may reduce its occurrence. Our study didn't have scope for chemical examination of the stones, which would be helpful for clear differentiation of the causes.

\section{REFERENCES}

1. Theise, N. D. (2015). Liver and gallbladder. In: Kumar, Abbas, Aster, editors. Robbins \& Cotran Pathologic basis of disease. South Asia ed. Vol 2. Elsevier; 875-880.

2. Adsay, N. V. (2010). Gallbladder, extrahepatic biliary tree, and ampulla. In: Mills, S. E., Carter, D., Greenson, J. K., Reuter, V. E., Stoler, M. H, editors. Sternberg's diagnostic surgical pathology. $5^{\text {th }}$ ed. Vol 2. Philadelphia: Lippincott Williams \& Wilkins; 1600-1651.

3. Nordenstedt, H., Mattsson, F., El-Serag, H., \& Lagergren, J. (2012). Gallstones and cholecystectomy in relation to risk of intra-and extrahepatic cholangiocarcinoma. British journal of cancer, 106(5), 1011-1015.

4. Everhart, J. E., Khare, M., Hill, M., \& Maurer, K. R. (1999). Prevalence and ethnic differences in gallbladder disease in the United States. Gastroenterology, 117(3), 632-639.

5. Zhu, X., Zhang, S., \& Huang, Z. (1995). The trend of the gallstone disease in China over the past decade. Zhonghua wai ke za zhi [Chinese journal of surgery], 33(11), 652-658.

6. Zaki, M., \& Al-Refeidi, A. (2009). Histological changes in the Human Gallbladder Epithelium associated with gallstones. Oman Medical Journal, 24(4):269-273.

7. Unisa, S., Jagannath, P., Dhir, V., Khandelwal, C., Sarangi, L., \& Roy, T. K. (2011). Populationbased study to estimate prevalence and determine risk factors of gallbladder diseases in the rural Gangetic basin of North India. $H p b, 13(2)$, 117125.

8. Albores-Saavedra, J. (2011). Arturo AngelesAngeles. Diseases of the gallbladder. Burt, A. D., Portmann, B. C., \& Ferrell, L. D. MacSween's pathology of the liver. $6^{\text {th }}$ ed. Elsevier; 563-600.
9. LaMorte, W. W., Matolo, N. M., Birkett, D. H., \& Williams Jr, L. F. (1981). Pathogenesis of cholesterol gallstones. Surgical Clinics of North America, 61(4), 765-774.

10. Paumgartner, G., \& Sauerbruch, T. (1991). Gallstones: pathogenesis. Lancet, 338:1117-1121.

11. Donovan, J. M., \& Carey, M. C. (1991). Physicalchemical basis of gallstone formation. Gastroenterology Clinics of North America, 20(1), 47-66.

12. Trotman, B. W. (1991). Pigment gallstone disease. Gastroenterology Clinics of North America, 20(1), 111-126.

13. Hattori, Y., Tazuma, S., Yamashita, G., Ochi, H., Sunami, Y., Nishioka, T., ... \& Tsuboi, K. (2000). Role of Phospholipase A2 in Cholesterol Gallstone Formation Is Associated with Biliary Phospholipid Species Selection at the Site of Hepatic Excretion. Digestive diseases and sciences, 45(7), 1413-1421.

14. Usui, R., Ise, H., Kitayama, O., Suzuki, N., \& Matsuno, S. (1991). Pathogenesis of black gallstones associated with hemolytic disease. Nihon Shokakibyo Gakkai zasshi= The Japanese journal of gastro-enterology,88(7), 1426-1435.

15. Donovan, J. M. (1999). Physical and metabolic factors in gallstone pathogenesis. Gastroenterology Clinics of North America, 28(1), 75-97.

16. Velanovich, V. (1997). Biliary dyskinesia and biliary crystals: a prospective study. The American surgeon, 63(1), 69-74.

17. Kouroumalis, E., Hopwood, D., Ross, P. E., Milne, G., \& Bouchier, I. A. (1983). Gallbladder epithelial acid hydrolases in human cholecystitis. Journal Pathology, 139:179-191.

18. Beena, D., Shetty, J., \& Jose, V. (2017). Histopathological spectrum of diseases in gallbladder. National Journal of Laboratory Medicine, 6(4):6-9.

19. Karlatti, S. S., \& Kumar, G. R. (2016). Incidence of Various Types of Gallstones in Patients of Cholelithiasis in Belgavi. International Journal Science Study, 4(7):21-23.

20. Awasthi, N. (2015). A retrospective histopathological study of cholecystectomies. International Journal of Health \& Allied Sciences, 4(3), 203-206.

21. Mohan, H., Punia, R. P. S., Dhawan, S. B., Ahal, S., \& Sekhon, M. S. (2005). Morphological spectrum of gallstone disease in 1100 cholecystectomies in North India. Indian journal of surgery, 67(3):140-142. 
22. Goyal, S., Singla, S., \& Duhan, A. (2014). Correlation between gallstones characteristics and gallbladder mucosal changes: A retrospective study of 313 patients. Clinical Cancer Investigation Journal, 3(2), 157-161.

23. Sharma, I., \& Choudhury, D. (2015). Histopathological patterns of gall bladder diseases with special reference to incidental cases: a hospital based study. Int J Res Med Sci,3(12), 3553-3557.

24. Kumari, G., Deshpande, K. A., \& Roy, S. (2018). Clinicopathological Study of Gallbladder Lesions: Two Years Study. Annals of Pathology and Laboratory Medicine, 5(5):456-462.

25. Murmu, S., Topno, V. J., \& Baitha, B. (2017). Histopathological study of gallbladder lesions in East Singhbhum, Jharkhand. IOSR Journal of Dental and Medical Sciences 16(2):1-3.
26. Mondal, B., Maulik, D., Biswas, B. K., Sarkar, G. N., \& Ghosh, D. (2016). Histopathological spectrum of gallstone disease from cholecystectomy specimen in rural areas of West Bengal, India-an approach of association between gallstone disease and gallbladder carcinoma. Int $J$ Community Med Public Health, 3, 3229-35.

27. Kumar, H., Dundy, G., Kini, H., Tiwari, A., \& Bhardwaj, M. (2018). Spectrum of gallbladder diseases-A comparative study in North Vs South Indian population. Indian Journal of Pathology and Oncology, 5(2), 273-276.

28. Nayak, G. (2016). A clinicopathological study of cholelithiasis in an eastern Indian population. International Journal Phar Bio Science, 7(3): 611 . 